Investigations

\title{
Education, Roles and Responsibilities of Nurse Practitioners in Quebec, Canada: A Qualitative Study
}

\author{
Claire Chapados \\ Department of Nursing, University of Montreal, Canada
}

\section{Article history}

Received: 31-12-2014

Revised: 10-02-2015

Accepted: 09-06-2015

E-mail: claire.chapados@umontreal.ca

\begin{abstract}
A description of the nurse-practitioner Master's of Nursing program in the Faculty of Nursing of the Université de Montréal in Quebec, Canada, is followed by a presentation of an exploratory, qualitative study conducted with 14 nurse practitioners in order to elicit a better understanding of their roles and responsibilities.
\end{abstract}

Keywords: Nurse Practitioner, Education, Roles and Responsibilities, Qualitative Study

\section{Introduction}

The role of the Nurse Practitioner (NP) has made progress in Quebec since the year 2000. In 2002 Quebec universities established NP programs and in January 2003 the legislature passed amendments to the Professional Code to foster development of the role. In 2004 Quebec's Order of Nurses (Ordre des infirmières et infirmiers du Québec (OIIQ)) and College of Physician (Collège des médecins du Québec (CMQ)) brought out joint guidelines for nurse practitioners and since 2005 NPs have been working in clinical settings. In 2010 there were 57 working in four specialties: cardiology, neonatology, nephrology and primary care. In Ontario, meanwhile, 800 NPs were working in primary care and in the United States more than 100,000 were engaged in various areas of medical practice (OIIQ, 2009). Since 2012 in Quebec, 150 NPs have been practising in 15 healthcare institutions.

Green (2013) reports thirteen different titles, a variety of regulations and a multiplicity of definitions around the world for what we term "nurse practitioners."

\section{OIIQ Definition}

An NP is a nurse holding a specialist certificate who provides advanced nursing care and performs medical activities authorized by a regulation of the CMQ to manage acute and chronic health problems in a particular area of specialization (neonatology, cardiology, nephrology, primary care). NPs must possess expertise in this clinical area acquired principally through a graduate (master's-level) education program in nursing and medicine established by a regulation of the OIIQ.

Most of an NP's practice is devoted to providing direct care centring on treatment and follow-up for patients presenting an acute or chronic health problem in a specialty or primary care. They possesses the competencies required to assess patient health, prescribe and interpret diagnostic tests, prescribe medical and pharmacological treatment and apply invasive techniques for diagnostic or therapeutic purposes. They also emphasizes health promotion and disease prevention through counselling, health-behaviour education and the development of self-care abilities. Extensive knowledge and expertise in her area of specialization enable her to take leadership both in her clinical practice and in her relations with nursing colleagues and other professionals. In addition, they contributes to educating future NPs, developing research and implementing clinical innovations. (OIIQ, 2010 Addendum; p. 9) (Translated from French).

\section{Background}

The development of the role of the NP varies greatly from a country to the other one. The United States had already established the category of the NPs in the middle of decade 60. The United Kingdom and Finland also have a long experience of various forms of collaboration between the doctors and nurses (Delamaire and Lafortune, 2010). The number NPs in primary care progresses has small steps in Canada. In 2007, we counted 1346 by comparison has 140000 , mainly, in primary care, in the United States (MSSS and MELS, 2009). The Canadian and international studies made on the role of the NPs demonstrate no negative result as for the efficiency of the NPs and the satisfaction of the patients (MSSS and MELS, 2009). Several studies devoted to the question of the role NPs demonstrate similar results compared with the medical role. Callaghan (Walsh, 2006) mentioned that is very important that nurse practitioner have advanced knowledge derived from education and experience for more autonomy and authority. Indeed, the 
results are comparable in what concerned the satisfaction of the patients, the health, the costs of health services and the procedures of care (Horrocks et al., 2002; Mundiger et al., 2000, see Quinland and Robertson, 2013).

For Hanson and Spross (2009), the communication is in the heart of all the interactions with the other health professionals and is a part integral of the collaboration, she must be cultivated. Charlton et al. (2008) note in their review of literature, that a clear and effective communication, on patient-centred, thereby increase the satisfaction, adherence to treatment plans and have a significant effect on patient health.

In another study, Quinland and Robertson (2013) demonstrate that NPs plays a crucial role in the facilitation of the mutual understanding between the others health workers in the teams. The NPs are part of a team, collaborating with registered nurses, physicians andother stakeholders and foster interprofessional collaboration (CNA, 2011a), very important for improving access to patient-centred health care (CNA, 2011b). They holds the power communicative the greatest in the team and which is not still included (Quinland and Robertson, 2013) and could be the event is an opportunity for competition among health professionnals. Another study (Weiland, 2008) that demonstrated how other factors influence the ability of NPs to practice as independent.

Another study recently (Poghosyan et al., 2015) showed that to promote the role of the NPs and promote a healthy work place and improve patient care, the administrators should reinforce the positive role of NPs in organization.

\section{Education Program}

The aim of the NP master's program is to enable nurses to perform interventions that fall outside usual nursing practice by providing medical in addition to nursing care. In the course of the program, students acquire extensive fundamental knowledge of biomedical sciences, develop complementary skills and are constantly required to analyze and organize information so that they can make appropriate clinical decisions. In their practice, they will act as consultants and educators and be an important resource for their nursing colleagues and other health care professionals (UdeM, 2015).

Entrance Requirements:

- Bachelor's degree in nursing or equivalent with a grade average of at least 3.0 out of 4.3

- Curriculum vitae

- Letter of intent or motivation

- Three course credits in each of the following: statistics and physical examination

- Three letters of reference (from a physician in the selected specialty, a nurse clinician specialist or nurse consultant or other executive nurse) outlining the candidate's professional qualifications
- A minimum of 2 years (3,360 hours) of full-time clinical experience acquired over the last five years

- Proof of OIIQ license to practise

- Interview dealing with the following: Previous experience in the selected specialty, knowledge of the role, communication skills, autonomy, adaptability, ability to work in a team, accept criticism, intellectual curiosity, competence in English reading, clinical scenarios

\section{Program Options}

NP students at the Université de Montréal must select a specialization in one of the following areas: cardiology, nephrology or primary care. They must complete both the Master of Nursing (45 credits), the complementary diploma (16 to 25 credits) in Specialized Care and specialized internship to be eligible to sit the OIIQ examination for the title of Nurse Practitioner. They must take the Master's and Specialized Care courses concurrently and complete a clinical internship of about six months at the end of their studies.The program is offered fulltime over two years or half time over three years.

Evaluation during the internship will focus on:

- Clinical competencies, including the knowledge, clinical skills and judgment that an NP must possess to assess health

- Communication and collaboration with patients, their families and members of the inter- and intradisciplinary team, which are integral aspects of the practice

- Professional development as evidenced by improved practice and efficiency in terms of knowledge retention; professional activities; and clinical leadership, performing an advisory role in the healthcare team and sharing evidence-based knowledge

- Professionalism and ethics in the promotion and maintenance of the health and well-being of her clients; acting as a role model and conducting her practice professionally and with integrity; respecting the rights of patients and their family; and fostering their participation in decisions regarding diagnosis and treatment

Evaluation instruments have been developed to assess the competencies, taking into account both medical and nursing aspects of care.

During the internship each student is paired with a supervising nurse practitioner who acts as a role model. The supervisor identifies clinical situations to meet the requirements of the internship; supervises the intern's interventions; stimulates the student's reflection and clinical reasoning; provides feedback; and participates in evaluating the candidate. The supervising nurse practitioner is in turn backed up by a clinical educator 
tasked with providing the interns with support and guidance and leading clinical encounters; she shares responsibility for the interns' evaluation with the supervising physician. The clinical educator is herself guided by a professional development officer who oversees the evaluations, works closely with the program head and supports her over the course of the students' studies.

\section{Certification Examination}

To practise autonomously, the candidate must pass the examination for a specialist certificate in the area concerned. The examination covers both theoretical and clinical aspects of the program and combines three evaluation instruments developed jointly by the OIIQ and the CMQ:

- A written "short answer open-ended question" type examination

- A Structured Oral Assessment (SOA)

- And an Objective Structured Clinical Examination (OSCE)

If she passes, the candidate will obtain a specialist certificate issued by the OIIQ allowing her to use the title of "Nurse Practitioner."

\section{Goal of the Study}

To understand the different roles and responsibilities of NPs (OIIQ, 2010)*

\section{Clinical Practice}

"NPs determine Patient's Health problems and collaborates with the Treating Physician to establish the Patient's care and medical treatment priorities, proceed to the exhaustive evaluation of the patient's health by privileging a global approach, conducts patient's follow-up and provide care to patients presenting complex, chronic health problems or acute episodes, exercise medical activities enumerated in the article 36.1 of the Nurse's Act. Order and interpret diagnosis exams, use invasive diagnostis techniques or presenting risks of damage, manage medicinal therapy and prescribe medical treatments and participate in the elaboration and implementation of education programs for patients and families (p.11)."

\section{Clinical Support}

"NPs participate in the elaboration and evaluation of Medical and Nursing protocols as well as the standards of practice of care for the patient, act as a personresource for her interdisciplinary team and Reference Centers (p.12)." NPs participate in committee and working groups focusing on continuous improvement of the quality of care for the field of specialization.

\section{Training and Teaching}

NPs participate in university teaching and supervision programs of future NPs, contribute to the improvement of patient's care by influencing the clinical practice of the nurses (p.12). NPs maintain and develop their knowledge and competence.

\section{Research}

"NPs analyze and interpret the recent researches and integrate relevant and evidence-based results into their clinical practice, use the clinical innovations from researches to improve quality of care to the patients and to their close relatives, define clinical problems and collaborate to the research projects in Patient's care and medical clinical research, contribute to the life of their work environment and the promotion of the profession, notably by lecturing or publishing at local, regional, national or international levels (p.12)"

*Translated from French

\section{Methodology}

Type of Study

Exploratory qualitative approach.

\section{Population}

A multidisciplinary sample constituted through purposive sampling. The inclusion criteria were:

- French-speaking

- Nurse practitioner with one year of experience in the area of specialization

- Physician

\section{Data Collection}

Data collection was conducted from December 2010 to November 2011 using semi-directed, 60-min, individual interviews. A two-part questionnaire was developed for the purpose: the first part concerned the conduct of health assessments by NPs (Chapados, 2013); the second part dealt with roles and responsibilities. Two more questions inquired into the NPs' level of satisfaction and whether they would choose to enter the program if they had to do it over again.

\section{Method of Data Analysis}

The listening to recorded notes and the verbatim transcription of recording was processed by the researcher and took $58 \mathrm{hr}$ to complete. Many readings of the experiences of NPs done gain a preparatory familiarization with the classification work and to outline the text as it fit into the system of catagorization. The analysis and interpretation of the data were built from the pinciples and techniques of data analysis 
developed by Miles and Huberman (2003). Their conception consists of three activities: the condensation, or reduction, of the data; the presentation of the data; and the development/verification of the conclusions. It's cyclic and interactive process. The data grouped together and analyzed in terms of categories related to roles and responsibilities.

\section{Ethical Considerations}

The study was approved by the ethics committee for research on human subjects at the Université de Montréal before beginning the collection of data. All the participants received an information letter and a consent form for their signature in which they acknowledged they had the right to withdraw from the study at any time. The information collected was recorded and destroyed on completion of the study. Participant anonymity was assured.

\section{Results}

\section{Sociodemographic Data}

- 14 NPs (5 men and 9 women) took part in the study. Their ages ranged from 29 to 57 years; the average age was 41 years. Six of the NPs work in cardiology care, 5 in nephrology care and 3 in primary care.

- 2 family physicians areas:

The NPs' practise with clienteles in the following

Cardiology

- Heart failure clinic

- Ambulatory care unit

- General cardiology

- Rhythmology

- Cardiac surgery

- Transplantation

- Coronary care unit

- Haemodynamics (OIIQ, 2006a)

Nephrology

- Haemodialysis unit

- Predialysis clinic

- Peritoneal dialysis unit

- Kidney transplant unit (OIIQ, 2006b)

Primary care:

- Newborns

- Children

- Adolescents

- Adults

- Pregnant women

- The elderly
(Patients presenting with a common health problem or a stable chronic disease, pregnancy monitoring (OIIQ, 2014))

\section{Clinical Practice}

More than $80 \%$ of the NPs' practice is in direct care. They conduct health assessments and clinical examinations, spending 30 to $60 \mathrm{~min}$ with each of 10 to 25 patients a day. They also perform medical activities: adjusting drug therapy, making diagnoses, adjusting medical treatment, prescribing laboratory tests, providing telephone follow-up care and supporting families through the treatment process.

All the NPs stated that the health assessment and the clinical examination are integral to their duties and that carrying them out entails reinforcement of important clinical skills: use of the systems approach (3 NPs); advanced clinical reasoning ( $5 \mathrm{NPs}$ ); the ability to draw connections (1 NP); and mastery of the theoretical concepts for conducting physical examinations (3 NPs) and taking medical histories properly (1 NP). Two NPs felt they were not as competent to conduct cardiovascular and ophthalmological examinations. Two NPs said it was essential to stay up to date with new practices and guidelines and to be on the lookout for anything new in their area of specialization, such as infectious diseases and different bacteria, strains and antibiotics.

One NP noted a difference in his reasoning from when he worked as a nurse clinician. In physical examinations of children, he had not really tried to make differential diagnoses or diagnostic hypotheses; rather he asked about the medical history and relied on what the mother told him.

In terms of collaboration, the NPs maintained that they still face resistance due to a lack of understanding. Their clinician colleagues question the role of the nurse practitioner but approach them with greater respect when they see the NP is autonomous, available and accessible. They encounter different problems with other professionals who are more resistant. Physicians, pharmacists, social workers, nutritionists, intensivists and internists have concerns about "who does what." They wonder about overlap between their fields and are afraid of the NP encroaching on their area of practice. Delamaire and Lafortune (2010) have noted these issues in their work.

NPs have to demonstrate their competencies and make the point that the work they do complements that of the other professionals. Once their role is understood and well defined, they consider themselves to be part of the team and feel better integrated in it.

Some of the professionals say that nurses who sign up for the NP program do so because they cannot gain admission to medical school. Many physicians believe NPs do not have enough training to carry out the medical tasks assigned to them. Physicians have expectations about the performance of NPs similar to 
those they have of fourth-year medical residents. If NPs can operate at that level, many physicians have a trusting relationship with them.

Some pharmacists contact their professional order to find out if NPs are actually authorized to write prescriptions. It should be pointed out that, while nurse practitioners have some prescribing latitude, pharmacists benefit from NPs'clinical-assessment skills.

\section{Clinical Support}

NPs are accessible resource persons, available closeat-hand for nurse clinicians; they are indeed an important, indispensable, comprehensive source of reference in clinical settings. Some NPs develop and evaluate medical and nursing protocols. They provide support in client assessment.

\section{Training and Teaching}

Of the fourteen participating NPs, two are developing teaching programs; one conducts training both in her workplace and elsewhere; three provide training on physical examinations and the Problem-Based Learning (PBL) approach at a medical school; one is a supervisor for NP internships; and one teaches nursing courses at the college level.

\section{Research}

Two NPs in nephrology are taking part in a number of medical-research projects, including one national study. Three NPs in cardiology are participating in research on nursing and medicine and read research articles. Three NPs in primary care aver that it is hard to conduct research and that they must choose between research and teaching.

All the NPs are members of the Association des infirmières praticiennes spécialisées du Québec (AIPSQ) and a number of them present papers at conferences and seminars.

\section{Physicians' Views}

According to the participating physicians, NPs perform full health assessments; and the medical histories they take and physical examinations they conduct are complete and accurate. The physicians think that NPs' provide comprehensive patient management, spend more time with patients and are more readily available to respond in emergencies. For "patients with a complex family or social history, NPs know the resources and find solutions quickly (Translated from French)." The physicians report that NPs take good care of their patients and that the patients are satisfied and say so. The physicians trust the nurse practitioners and have only positive comments to make about them (Chapados, 2013).

\section{Views of a Cardiology Nurse Practitioner}

"The added value [lies in] being different, doing more. It's not just being an MD's right hand or left hand for clients. The nursing and medical components are what make all the difference (Translated from French)" (Chapados, 2013).

\section{Satisfaction with the Role}

Most of the NPs (11/14) are satisfied with their role, saying they have acquired extensive fundamental knowledge that advances their professional development. However, they are dissatisfied with their remuneration and contend they earned more as nurse clinicians, when they received care-unit, night and week-end premiums. They now have to work long hours and have greater responsibilities and bureaucratic duties as well. Some are unhappy they are not consulted to assess patients in other areas of their specialty and several would like to be involved in nursing research projects.

All the NPs maintain that their role constitutes an added value. In biopsychosocial terms, there is no question but that patients receive better care with a comprehensive approach. The NPs are more autonomous, can make decisions and take their time with patients and improve follow-up care. They accelerate patient management and can see that their patients are satisfied. The participating NPs thus confirm the findings of the study by Charlton et al. (2008) on patient-centred communication.

\section{Taking the Program Over Again}

The NPs were asked if they would take the program if they had to do it over again. Eight unhesitatingly said "yes" because the practice is interesting and is essential for their clientele and they feel they are "making a difference" every single day.

Two NPs are not sure they would do it again. They point to the less rewarding aspects: the lack of support from general and nursing management, the demanding program, physician resistance, intimidation, lack of trust, unattractive pay and the lack of financial support for continuing professional development. One of them expressed himself as follows:

You think you know everything because you've been working for 20 years, but you've become a novice again. You're really lost. I was ready to give up after the first month. How am I going to get through it all? I'd done my bachelor's degree in 1986. It was totally hard. Another student helped me a lot. I learned a lot (Translated from French). 
One NP said he would do it over but in another specialty, adding that the specialist physicians are unappreciative and think he ought to do more medically.

The two NPs who said they would not take the program if they had to do it over again cited the long, exhausting hours of work it entailed every day.

Another NP did not respond because the program did not meet his expectations and he said he did not receive the support he felt he should have.

\section{Discussion}

NPs play a key role in and constitute an added value for, the Quebec healthcare system. They possess the competencies they need to carry out their duties, thus corroborating the CNA's outline of requirements for the practice (2010). They collaborate with the attending physician to identify patient health problems and to set priorities for care and treatment. They enable patients to become active partners and motivate them to make the necessary personal changes to effectively self-manage their care. They intervene quickly, avert delays, prevent complications, provide active follow-up care and guide patients to other community services and resources. They enhance the quality of care and the accessibility of services for clients while reducing the healthcare costs associated with chronic diseases. As DiCenso (2013) said in a lecture in Melbourne, Australia, on the changing scopes of practice, in Canada no further evidence is needed:"NPs increase effectiveness and lower costs (Translated from French).

The results also confirm findings of several previous studies, those of Delamaire and Lafortune (2010), Hanson and Spross (2009), Charlton et al. (2008) and CNA (2011a; 2011b) on collaboration and communication. Therefore, this study allowed to highlighting the advantages and disadvantages the role of the nurse practitioners. Advantages included satisfaction of the patients, decrease in health care costs, clear and effective communication with patients. Disadvantages included the lack of knowledge of the roles and overlap with others professionals, remuneration, lack of support of general management and department of nursing. The results of this study reveal that the most significant barrier to the integration of the nurse practitioner in the health institution is unfamiliarity the role. Studies could be carried with the administrators for a better understanding of their perception and the type of relationship they have with them and it, to give a support for a better practice.

Finally, all the research that I have read on nurse practitioners indicate that there is still variability in the education and practice for NPs. Unlike the United States, Canada, especially in Quebec, does not have any standards for distance education, educational program are not consistently delivered at a master's level of education across the country (CNA, 2009).
Recommendations for practice.

It is essential of:

- Provide information about the role of the nurse practitioners

- Support from other NPs, administrators, nurses, physicians and other health professionals for better collaboration with other members of the care team

- Take continuing education very seriously and encourage the continuous education among NPs in order continue ongoing professional development of skills

- Promote inter professional education

- Permit better integration of the nurse practitioner in health institution

\section{Conclusion}

This paper provides a description of the education program for nurse practitioners in the Universite de Montréal's Faculty of Nursing, widely considered a leader in the discipline. It further reports the results of a study examining the roles and responsibilities of NPs and of the factors that, despite the impediments to progress the practice faces, motivate them to pursue development of their abilities in carrying out their duties and making "a difference." NPs are proud of being a source of reference for their colleagues and believe strongly in inter- and intra-professional collaboration while acknowledging and respecting their limitations, by refusing to assume any responsibilities not delegated to nurse practitioners.

\section{Acknowledgment}

The author likes to take this opportunity to thank all of the participating Nps and physicians for their valuable contributions to this research.

\section{Funding Information}

The authors have no support or funding to report.

\section{Ethics}

This article is original and the majority of the writings were not published. Some extracts are fired by a French publication in (Chapados, 2013) but the author notes the reference. The author confirms have read and approved the manuscript and consider that its publication raises no ethical or moral difficulties.

\section{References}

Chapados, C., 2013. L'évaluation de la santé par les infirmières praticiennes spécialisées: Des IPS témoignent. Perspective Infirmière, 10: 26-30. 
Charlton, C.R., K.S. Dearing, J.A. Berry and M.J. Johnson, 2008. Nurse practitioners' communication styles and their impact on patient outcomes: An integrated literature review. J. Am. Acad. Nurse Practit., 20: 382-388.

CNA, 2009. Recommendations of the Canadian Nurse Practitioner Initiative. 1st Edn., Canadian Nurses Association, Ottawa, ISBN-10: 1551193213, pp: 40.

CNA, 2010. Canadian Nurse Practitioner Core Competency Framework. Ottawa.

CNA, 2011a. Nurse practitioners it's about time. CNA.

CNA, 2011b. Position Statement. Interprofessional collaboration. CNA.

Delamaire, M.L. and G. Lafortune, 2010. Les pratiques infirmières avancées: Une description des expériences dans 12 pays développés. OCDE.

DiCenso, A., 2013. Changing scopes of practice. Proceedings of the ICN 25th Quadrennial Congress, (QC' 13), Equity and Access to Health Care Melbourne, Australia.

Green, A., 2013. Nurse practitioners/advanced practice nursing network (oral presentation). Proceedings of the ICN 25th Quadrennial Congress, May 18-23, Equity and Access to Health Care. Melbourne, Australia.

Hanson, C.M. and J.A. Spross, 2009. Collaboration. In: Advanced Practoice Nursing: An Integrative Approach, Hamric, A.B. J.A. Spross and C.M. Hanson (Eds.), Saunders Elsevier, pp: 283-314.

Horrocks, S., E. Anderson and C. Salisbury, 2002. Systematic review of whether nurse practitioners working in primary care can provide equivalent care to doctors. British Med. J., 324: 819-823. DOI: 10.1136/bmj.324.7341.819

Miles, M.B. and A.M. Huberman, 2003. Analyse des Données Qualitatives. 2nd Edn., De Boeck Supérieur, Bruxelles, ISBN-10: 2744500909, pp: 626.

MSSS and MELS, 2009. L'infirmière Praticienne Spécialisée en Soins de Première ligne. 1st Edn., Bilan et orientations de la pratique au Québec. Québec, Canada. pp: 55.

Mundiger, M.O., R.L. Kane, E.R. Lenz, A.M. Totten and W.Y. Tsai et al., 2000. Primary care outcomes in patients treated by nurse practitioners or physicians: A randomized trial. J. Am. Med. Assoc., 283: 59-68.
OIIQ, 2006a. Étendue des activités médicales exercées par l'infirmière praticienne spécialisée en cardiologie. Document conjoint OIIQ et Collège des médecins du Québec (CMQ). Montréal.

OIIQ, 2006b. Étendue des activités médicales exercées par l'infirmière praticienne spécialisée en néphrologie. Document conjoint OIIQ et Collège des médecins du Québec (CMQ). Montréal.

OIIQ, 2009. Les infirmières praticiennes spécialisées: Un rôle à propulser, une intégration à accélérer. Mémoire. Bilan et perspectives de pérennité. Montréal.

OIIQ, 2010. Lignes directrices sur les modalités de la pratique de l'IPS. Addendum (Rôles et responsabilités). Document conjoint OIIQ/CMQ. Montréal.

OIIQ, 2014. Lignes directrices: Pratique clinique de l'infirmière praticienne spécialisée en soins de première ligne. 2nd Édn., Document conjoint OIIQ et Collège des médecins du Québec (CMQ). Montréal.

Poghosyan, L., J. Shang, J. Liu, H. Poghosyan and N. Liu et al., 2015. Nurse practitioners as primary care providers: Creating favorable practice environments in New York State and Massachusetts. Health Care Management Rev., 40: 46-55.

Quinland, E. and S. Robertson, 2013. The communicative power of nurse practitioners in multidisciplinary primary healthcare teams. J. Am. Assoc. Nurse Practit., 25: 91-102.

UdeM, 2015. Université de Montréal.

Walsh, M., 2006. Nurse Practitioners: Clinical Skills and Professional Issues. 2nd Edn., Butterworth Heinemenn Elsevier, pp: 381.

Weiland, S.A., 2008. Reflections on independence in nurse practitioner practice. J. Am. Acad. Nurse Practit., 20: 345-352.

Claire Chapados is a professor in the Faculty of Nursing at the Université de Montréal. She played an active part in developing the Faculty's NP program from 2003 to 2006 and headed the program from 2006 to 2011 and from 2013 to 2014. 